\title{
Clinical and molecular genetics of neonatal diabetes due to mutations in the insulin gene
}

\author{
Julie Støy • Donald F. Steiner • Soo-Young Park • \\ Honggang Ye • Louis H. Philipson • Graeme I. Bell
}

Published online: 12 October 2010

(C) The Author(s) 2010. This article is published with open access at Springerlink.com

\begin{abstract}
Over the last decade our insight into the causes of neonatal diabetes has greatly expanded. Neonatal diabetes was once considered a variant of type 1 diabetes that presented early in life. Recent advances in our understanding of this disorder have established that neonatal diabetes is not an autoimmune disease, but rather is a monogenic form of diabetes resulting from mutations in a number of different genes encoding proteins that play a key role in the normal function of the pancreatic beta-cell. Moreover, a correct genetic diagnosis can affect treatment and clinical outcome. This is especially true for patients with mutations in the genes $K C N J 11$ or $A B C C 8$ that encode the two protein subunits (Kir6.2 and SUR1, respectively) of the ATP-sensitive potassium channel. These patients can be treated with oral sulfonylurea drugs with better glycemic control and quality of life. Recently, mutations in the insulin gene (INS) itself have been identified as another cause of neonatal diabetes. In this article, we review the role of INS mutations in the pathophysiology of neonatal diabetes.
\end{abstract}

Keywords ER stress - Insulin - Maturity-onset diabetes of the young $\cdot$ Neonatal diabetes . Type 1 diabetes $\cdot$ Unfolded protein response

J. Støy $(\bowtie)$

Department of Internal Medicine and Endocrinology, Aarhus University Hospital,

Nørrebrogade 44,

8000 Aarhus C, Denmark

e-mail: julistoe@rm.dk

D. F. Steiner - S.-Y. Park $\cdot$ H. Ye - L. H. Philipson • G. I. Bell Departments of Medicine, Human Genetics, and Biochemistry and Molecular Biology, The University of Chicago,

5841 S. Maryland Ave., MC1027,

Chicago, IL 60637, USA

\section{Introduction}

Insulin plays a key role in the regulation of glucose homeostasis with diabetes resulting from insulin deficiency, whether complete deficiency as in type 1 diabetes or relative deficiency as in type 2 diabetes. A genetic basis for diabetes is well established with some forms resulting from a mutation in a single gene (monogenic forms of diabetes) and others from a combination of common, and possibly rare, genetic variants acting together with environmental factors to affect risk of disease (polygenic forms of diabetes) [1]. Insulin was the first protein to be completely sequenced [2] with the amino acid sequence of bovine insulin determined by Sanger and his colleagues from 1951-1955. The amino acid sequence of human insulin was reported by Nicol et al. in 1960 and human proinsulin (the single-chain precursor to insulin) by Oyer et al. in 1971 [3-5]. The human preproinsulin cDNA and complete amino acid sequence of preproinsulin were identified by Bell et al. in 1979 and the cloning and the characterization of the human insulin gene by Bell et al. in $1980[6,7]$.

Studies of human insulin from nondiabetic and diabetic patients suggested that differences in sequence could be a genetic cause of diabetes but definitive proof was lacking (reviewed in Kimmel et al. 1967) [8]. The first mutant human insulin protein was identified by Tager and colleagues in 1979 and subsequently mutant proinsulin in 1981 in patients with hyperinsulinemia and hyperproinsulinemia, respectively, both very rare conditions with only 15 families reported to date [9-12]. Moreover, most patients with hyperinsulinemia or hyperproinsulinemia did not develop overt diabetes. These studies suggested that if mutations in the human insulin gene were a cause of diabetes, they were very rare and unlikely to be a significant factor contributing to disease. This view has 
now changed based on recent studies from our laboratory and others reporting the identification of many new mutations in the insulin gene in humans and mice [13-19]. Mutations in the human insulin gene (INS) are a common cause of permanent neonatal diabetes mellitus (PNDM). They can also result in diabetes diagnosed outside infancy with a diagnosis of type $1 \mathrm{~b}$ diabetes or maturity-onset diabetes of the young. They are also the cause of diabetes in two mouse models-the Akita and Munich mouse. Clinical studies of these patients and molecular and cell biological studies of the mutant insulin, preproinsulin and proinsulin proteins are providing new insight into the pathophysiology of diabetes as well as insulin biosynthesis [18, 19].

\section{Molecular structure of insulin and insulin biosynthesis}

Insulin is the major biosynthetic and secretory product of the beta cell accounting for $20 \%$ of total mRNA (100200,000 insulin mRNA molecules/cell), $10 \%$ of total cellular protein and $50 \%$ or more of total protein synthesis when maximally stimulated corresponding to $1.3 \times 10^{6}$ molecules of insulin/min [20, 21].

The initial product of translation of human insulin mRNA is a single chain precursor molecule, preproinsulin, a protein of 110 amino acid residues including the signal peptide of 24 amino acid residues. The emerging signal peptide first interacts with the signal recognition particle in the cytosol. This complex then interacts with the translocon on the ER membrane which targets the nascent proinsulin peptide chain into the ER. The signal peptide is rapidly cleaved and degraded and proinsulin then folds in the lumen of the ER forming the characteristic disulfide bonds of the insulin molecule. In proinsulin, the C-peptide bridges the B-chain and the A-chain via two pairs of basic amino acids (Arg-Arg and Lys-Arg, respectively) (Fig. 1). In mature insulin, the Cpeptide and the four basic residues have been excised and the $\mathrm{B}$ - and A-chains are connected covalently only by the two disulfide bonds between the B7-A7 and B19-A20 cysteines. A third intrachain disulfide bond connects A6 and A11 cysteines. The folding of proinsulin and disulfide bond formation are catalyzed by several classes of ER chaperone proteins. Only the fully folded native proinsulin protein can normally progress from the ER to the Golgi compartments. After transitioning through the Golgi apparatus, the proinsulin is concentrated and sorted into immature secretory granules in the transGolgi network. The proteolytic processing of proinsulin to insulin and C-peptide takes place mainly in the maturing secretory granules by cleavage sequentially at the B-chain-C-peptide junction by proconvertase (PC) $1 / 3$ and carboxypeptidase $\mathrm{E}$ (CPE) yielding des-31,32-proinsulin and then at the C-peptide-A-chain junction by PC2 and CPE yielding insulin and $\mathrm{C}$-peptide. Three molecules of Arg and one molecule of Lys are released during this process. Insulin and C-peptide are stored in the mature secretory granules and secreted in equimolar amounts [22].

\section{Insulin mutations in monogenic forms of diabetes}

\subsection{Insulin mutations and diabetes}

Insulin gene mutations as a cause of diabetes were identified independently by ourselves (Støy et al. 2007) and by Colombo et al. (2008) [13, 17]. We carried out a linkage analysis in a three-generation family with PNDM of unknown etiology. The results suggested that the putative diabetes gene was located on either chromosome 2, 3, 6 or 11. Cataloguing the genes under the linkage peaks of each of these chromosomes revealed two candidate genes-NEURODI and INS. There were no mutations in the coding region of NEUROD1. Sequencing of INS revealed the missense mutation G32S in affected family members suggesting that an INS mutation was responsible for PNDM in this family. The association of INS mutations with PNDM was confirmed by the identification of mutations in 15 additional probands. Interestingly, the majority of the mutations were not inherited but were de novo in origin. All were in the heterozygous state. Colombo et al. [17] used a candidate gene approach based on the fact that a mutation in the Ins 2 gene (the mouse homolog of the insulin gene in human) was the cause of diabetes (described as maturity-onset diabetes of the young) in the Akita mouse model of diabetes [18]. They identified seven different INS mutations in 9 probands with PNDM.

Mutations (in the heterozygous state) in INS have now been reported in 66 probands with a variety of diagnoses including PNDM, infancy-onset diabetes (i.e. diabetes diagnosed before 12 months of age), type $1 \mathrm{~b}$ diabetes (i.e. non-autoimmune type 1 diabetes (T1DM)), maturityonset diabetes of the young (MODY), and early-onset type 2 diabetes (T2DM) (Figs. 1-2 and Table 1) [13-17, 23-28]. There are multiple affected family members in 23/66 families. Of the 107 carriers in these families, 104 have diabetes and three have normal glucose tolerance.

In the large Exeter cohort of patients with PNDM diagnosed before 6 months of age, 14\% of patients born to non-consanguineous parents were found to carry a heterozygous INS mutation. The incidence of INS mutations in patients diagnosed with diabetes outside the neonatal period is less well defined, but is estimated to be less than $2 \%$. The mutations in $18 / 66(27 \%)$ of the probands were inherited from an affected parent whereas in the remaining 48 probands $(73 \%)$ the mutation was de novo in origin. In one family, two affected children with the same mutation were born to unaffected parents, neither of them carriers, suggesting that one of the parents was a germline mosaic. 


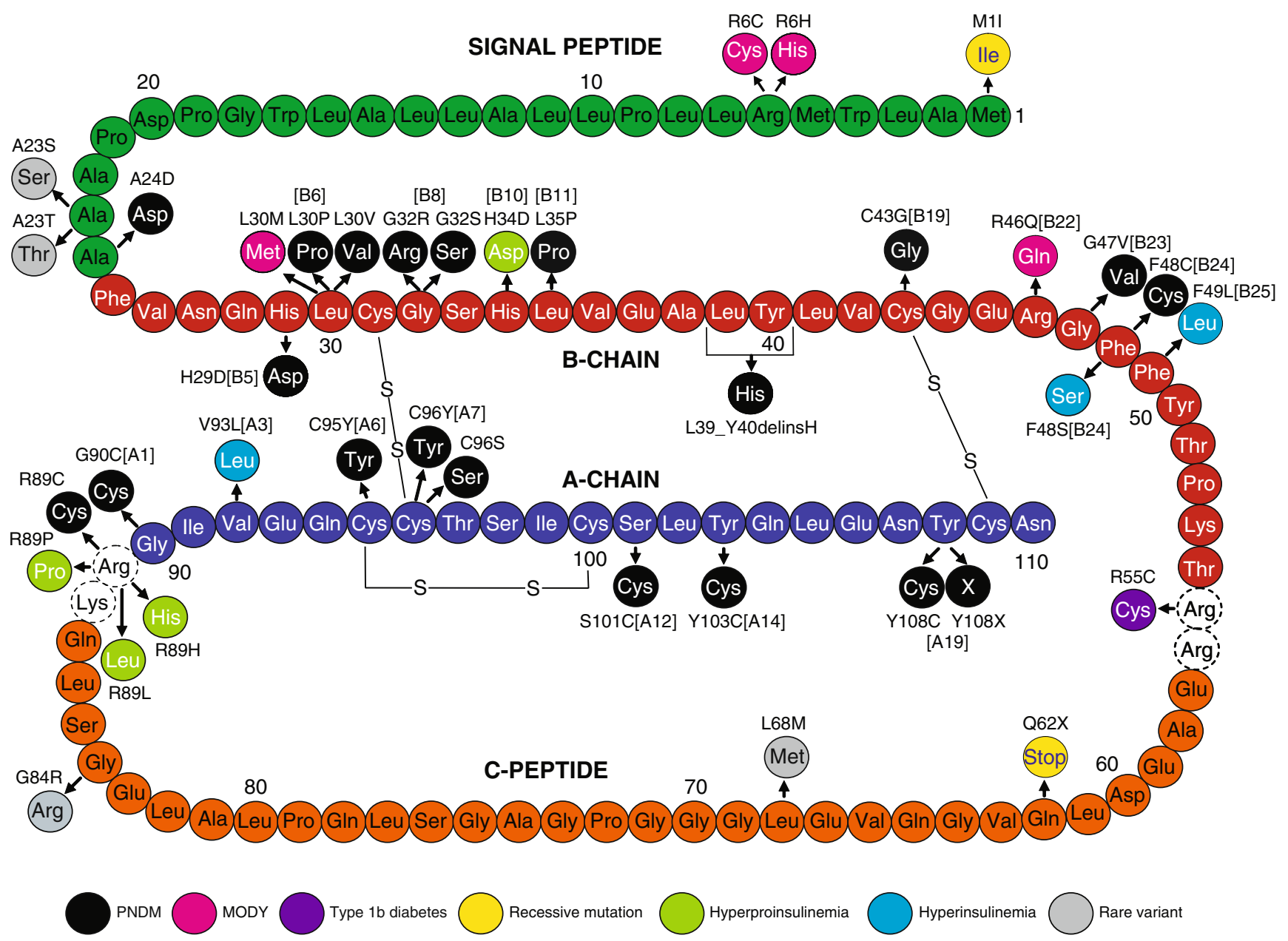

Fig. 1 Diagrammatic representation of the amino acid sequence of human preproinsulin (signal peptide-green, B-chain-red, C-peptideorange, A-chain-dark blue) indicating sites of mutations identified in patients with diabetes as well as hyperinsulinemia and hyperproinsulinemia. Mutations shown in black disrupt proinsulin folding and/or disulfide bond formation leading to permanent neonatal diabetes mellitus (PNDM); mutations in light blue do not impair folding but are associated with reduced insulin receptor binding potency (hyperinsulinaemia); mutations in light green are associated with hyperproinsulinaemia and either impair proteolytic processing to insulin or, in the case of $\mathrm{H} 34 \mathrm{D}$, aggregation and sorting into dense-core granules of the regulated secretory pathway. Mutations in pink and purple were found in patients with a diagnosis of maturity-onset diabetes of the young (MODY) and type $1 \mathrm{~b}$ diabetes, respectively. The $\mathrm{R} 55 \mathrm{C}$ mutation has been found in patients with a diagnosis of type $1 \mathrm{~b}$ diabetes as well as MODY. The mutations shown in gray (A23S, A23T, L68M and G84R) are rare variants without functional effects on proinsulin/insulin biosynthesis. The mutations shown in yellow are recessive mutations that affect insulin biosynthesis (mutation of the translation initiation Met) or cause the synthesis of a nonsense protein $(\mathrm{Q} 62 \mathrm{X})$
The diabetes-associated mutations lead to the synthesis of a structurally abnormal preproinsulin or proinsulin protein. The mutations are located in the signal peptide, the B-chain and Achain regions and the pairs of basic residues that flank the $\mathrm{C}$ peptide. Those located in the signal peptide impair the function of this domain of preproinsulin including absent or altered cleavage of the signal peptide. The mutations in proinsulin affect formation of the disulfide bonds linking the B-chain and A-chain as well as the intra-A-chain disulfide bond thereby leading to a misfolded proinsulin molecule that is retained in the ER impairing normal beta-cell function and resulting in cell death [17, 19, 29-31].

Garin et al. [32] recently reported recessive mutations in INS resulting in neonatal diabetes. These mutations affect proinsulin biosynthesis per se and function as null mutations, doing so by several different mechanisms. One mutation results in deletion of exons 1 and 2 of the insulin gene. There are several mutations located in the promoter region of the gene that result in decreased transcription. A mutation in the region encoding the 3 '-untranslated region of the mRNA affects polyadenylation and mRNA stability. Other mutations affect translation of insulin mRNA by mutation of the translation initiation codon, or lead to synthesis of a truncated proinsulin molecule (Figs. 1 and 3).

Homozygous mutations in INS have been reported in 15 families/21 patients. These patients were diagnosed with PNDM ( $67 \%$ of patients), type $1 \mathrm{~b}$ diabetes ( $9 \%$ of patients) 


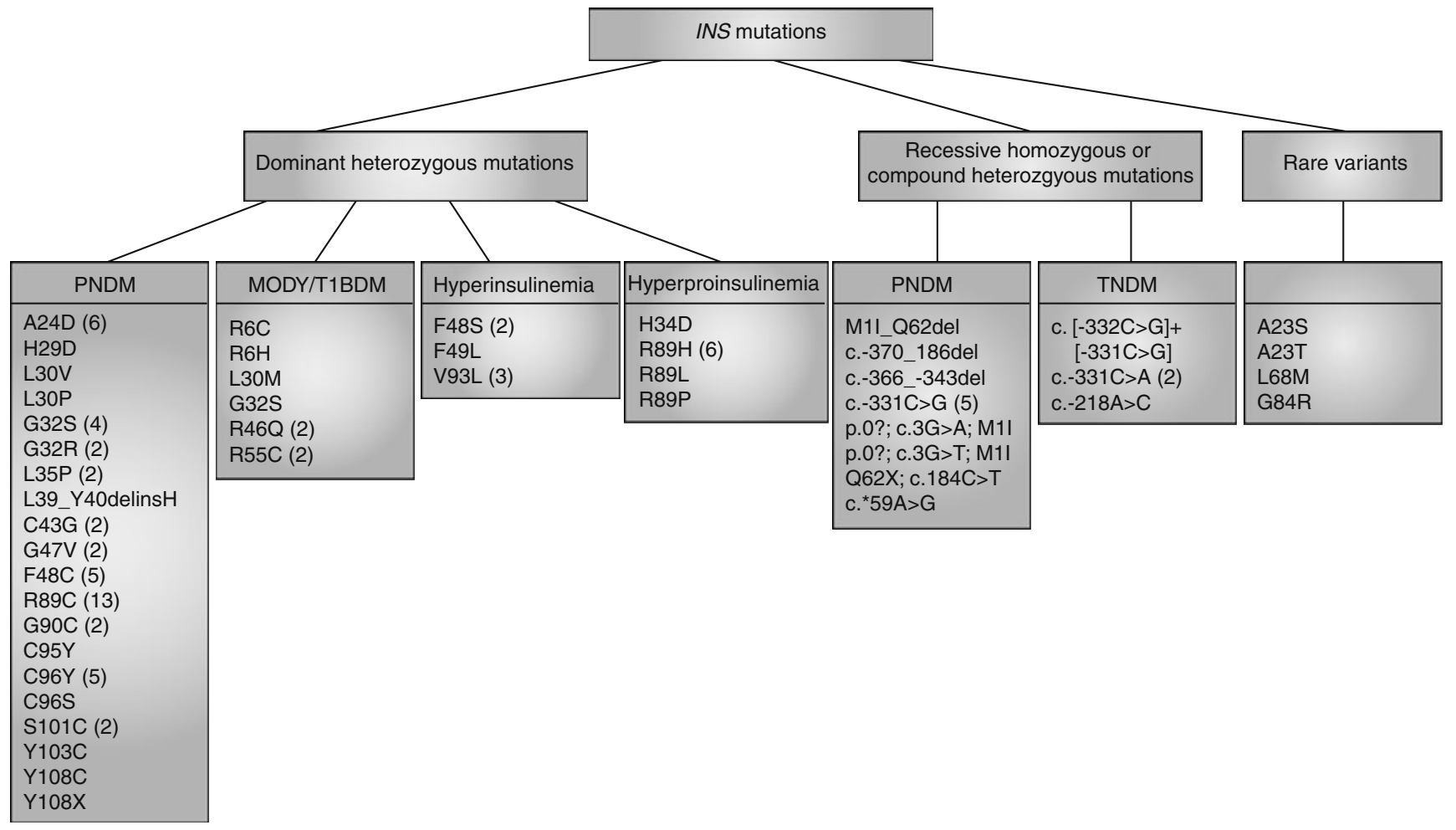

Fig. 2 Summary of human insulin gene mutations and disease phenotype. The numbers in brackets indicate the number of probands with that specific mutation. PNDM, permanent neonatal diabetes

and, in contrast to heterozygous INS mutation carriers, with transient neonatal diabetes mellitus (TNDM) $(24 \%$ of patients). Homozygous INS mutations are the most common cause of PNDM without extra-pancreatic features in patients born to consanguineous parents $(\sim 32 \%)$, but are a rare cause of neonatal diabetes in patients born to nonconsanguineous parents $(\sim 1 \%)$ [32].

\subsection{Characteristics of mutations}

All the mutations in the preproinsulin protein reported to date are shown in Fig. 1. In addition to the mutations associated with diabetes, hyperinsulinemia or hyperproinsulinemia, there are four mutations that are unlikely to be pathogenic: A23S, A23T, L68M and G84R [14, 23, 28] (Figs. 1 and 2). The mutation A23S has been reported to be associated with type $1 \mathrm{~b}$ diabetes. However, this site is not highly conserved amongst preproinsulin sequences and is Ser in the chimpanzee sequence strongly suggesting that it does not lead to diabetes (Fig. 4). Functional studies indicate that G84R does not affect proinsulin biosynthesis suggesting that the putative diabetes-associated mutation is not pathogenic [30].

The dominantly-acting diabetes-associated mutations involve 19/110 amino acids of preproinsulin and include 23 missense mutation, one nonsense mutation and one mellitus; TNDM, transient neonatal diabetes mellitus; MODY, maturity-onset diabetes of the young; T1BDM, type $1 \mathrm{~b}$ diabetes mellitus

insertion/deletion mutation. They are located in all regions of the preproinsulin molecule except the C-peptide: signal peptide (3 mutations), B-chain (12 mutations), A-chain (8 mutations) and pairs of basic amino acids that flank the C-peptide ( 2 mutations). The latter mutations are found at the enzymatic cleavage site between the B-chain and C-peptide (R55C) and the C-peptide and A-chain (R89C). Other mutations of Arg89 have been described in patients with hyperproinsulinemia. Thirteen mutations were identified in more than one proband (Fig. 2, Table 1) and mutations at five codons (A24D, G32S/R, F48C, R89C, and $\mathrm{C} 96 \mathrm{Y} / \mathrm{S})$ account for $56 \%(37 / 66)$ of all mutations identified to date. Six residues are sites for different amino acid substitutions: R6C/H, A23S/T, L30M/P/V, G32S/R, $\mathrm{C} 96 \mathrm{Y} / \mathrm{S}$ and $\mathrm{Y} 108 \mathrm{C} / \mathrm{X}$. Five mutations were identified in families where all affected family members were diagnosed with diabetes outside the neonatal period or infancy (R6C, $\mathrm{R} 6 \mathrm{H}, \mathrm{L} 30 \mathrm{M}, \mathrm{R} 46 \mathrm{Q}$ and $\mathrm{R} 55 \mathrm{C}$ ) highlighting the different effects of these various mutations on pancreatic beta-cell function. As noted above, A23S/T, L68M, and G84R are most likely rare variants that are not pathogenic and patients carrying these variant are not included in the genotype/phenotype analyses described below.

Ten different homozygous INS mutations have been reported to date [32]. Five homozygous mutations have been found in regions of INS affecting transcription or 
Table 1 Insulin gene mutations and diabetes

\begin{tabular}{|c|c|c|c|c|c|c|}
\hline \multirow[t]{2}{*}{ Location of mutation } & \multicolumn{2}{|l|}{ Mutation } & \multirow{2}{*}{$\begin{array}{l}\text { Homozygous/ } \\
\text { Heterozygous }\end{array}$} & \multirow{2}{*}{$\begin{array}{l}\text { Probands/ } \\
\text { Patients }\end{array}$} & \multirow{2}{*}{$\begin{array}{l}\text { Phenotype/Diagnosis } \\
\text { (Number of subjects) }\end{array}$} & \multirow[t]{2}{*}{ Reference } \\
\hline & Protein change & $\begin{array}{l}\text { Nucleotide } \\
\text { change }\end{array}$ & & & & \\
\hline $\begin{array}{l}\text { Promoter, signal peptide, } \\
\text { B-chain, C-peptide }\end{array}$ & - & $\begin{array}{l}\text { c. }-370-?+186+ \\
\text { ?del }\end{array}$ & Homozygous & $1 / 2$ & PNDM & {$[32]$} \\
\hline Promoter & - & c. $-366-343 \mathrm{del}$ & Homozygous & $1 / 2$ & PNDM & {$[32]$} \\
\hline Promoter & - & c. $-331 \mathrm{C}>\mathrm{A}$ & Homozygous & $2 / 2$ & TNDM & {$[32]$} \\
\hline Promoter & - & c. $-331 \mathrm{C}>\mathrm{G}$ & Homozygous & $5 / 9$ & $\begin{array}{l}\text { PNDM (6), TNDM (1), } \\
\text { T1BDM (2) }\end{array}$ & {$[32]$} \\
\hline Promoter & - & $\begin{aligned} \text { c. }-332 \mathrm{C}>\mathrm{G}+\mathrm{c} . \\
-331 \mathrm{C}>\mathrm{G}\end{aligned}$ & $\begin{array}{l}\text { Compound } \\
\text { heterozygous }\end{array}$ & $1 / 1$ & TNDM & {$[32]$} \\
\hline Promoter & - & c. $-218 \quad \mathrm{~A}>\mathrm{C}$ & Homozygous & $1 / 1$ & TNDM & {$[32]$} \\
\hline Signal peptide & p.0? (M1I) & c. $3 \mathrm{G}>\mathrm{T}$ & Homozygous & $1 / 1$ & PNDM & {$[32]$} \\
\hline Signal peptide & p.0? (M1I) & c. $3 \mathrm{G}>\mathrm{A}$ & Homozygous & $1 / 1$ & PNDM & {$[32]$} \\
\hline Signal peptide & $\mathrm{R} 6 \mathrm{C}$ & c. $16 \mathrm{C}>\mathrm{T}$ & Heterozygous & $1 / 3$ & MODY & {$[14]$} \\
\hline Signal peptide & $\mathrm{R} 6 \mathrm{H}$ & c. $17 \mathrm{G}>\mathrm{A}$ & Heterozygous & $1 / 4$ & $\begin{array}{l}\text { MODY/ T2DM / GDM / } \\
\text { Normal }\end{array}$ & {$[26]$} \\
\hline Signal peptide & $\mathrm{A} 23 \mathrm{~S}$ & c. $67 \mathrm{G}>\mathrm{T}$ & Heterozygous & $1 / 1$ & T1BDM* & {$[23]$} \\
\hline Signal peptide & $\mathrm{A} 23 \mathrm{~T}$ & c. $67 \mathrm{G}>\mathrm{A}$ & Heterozygous & $1 / 4$ & $\begin{array}{l}\text { T2DM (2) / IGT (1) / } \\
\text { Normal* }\end{array}$ & {$[28]$} \\
\hline Signal peptide & $\mathrm{A} 24 \mathrm{D}$ & c. $71 \mathrm{C}>\mathrm{A}$ & Heterozygous & $6 / 8$ & PNDM (7) / T1BDM (1) & {$[13,14,16]$} \\
\hline B-chain & $\mathrm{H} 29 \mathrm{D}$ & c. $85 \mathrm{C}>\mathrm{G}$ & Heterozygous & $1 / 1$ & PNDM & {$[14]$} \\
\hline B-chain & L30V & c. $88 \mathrm{C}>\mathrm{G}$ & Heterozygous & $1 / 1$ & PNDM & [17] \\
\hline B-chain & L30M & c. $88 \mathrm{C}>\mathrm{A}$ & Heterozygous & $1 / 6$ & MODY (5) / Normal & {$[26]$} \\
\hline B-chain & L30P & c. $89 \mathrm{~T}>\mathrm{C}$ & Heterozygous & $1 / 1$ & PNDM & {$[17]$} \\
\hline B-chain & G32S & c. $94 \mathrm{G}>\mathrm{A}$ & Heterozygous & $5 / 8$ & PNDM (7) / T1BDM (1) & {$[13,14,23,24]$} \\
\hline B-chain & G32R & c. $94 \mathrm{G}>\mathrm{C}$ & Heterozygous & $2 / 5$ & PNDM (4) / MODY (1) & {$[13,14]$} \\
\hline B-chain & L35P & c. $104 \mathrm{~T}>\mathrm{C}$ & Heterozygous & $2 / 2$ & PNDM & {$[14,17]$} \\
\hline B-chain & L39_Y40delinsH & $\begin{array}{l}\text { c. } 114 \_118 \\
\text { TCTCT }>\text { AC }\end{array}$ & Heterozygous & $1 / 1$ & PNDM & [17] \\
\hline B-chain & $\mathrm{C} 43 \mathrm{G}$ & c. $127 \mathrm{~T}>\mathrm{G}$ & Heterozygous & $2 / 3$ & PNDM (2) / T2DM (1) & {$[13,14]$} \\
\hline B-chain & R46Q & c. $137 \mathrm{G}>\mathrm{A}$ & Heterozygous & $2 / 6$ & MODY & {$[15,27]$} \\
\hline B-chain & G47V & c. $140 \mathrm{G}>\mathrm{T}$ & Heterozygous & $2 / 2$ & PNDM & {$[13,14]$} \\
\hline B-chain & $\mathrm{F} 48 \mathrm{C}$ & c. $143 \mathrm{~T}>\mathrm{G}$ & Heterozygous & $5 / 6$ & PNDM & {$[13,14]$} \\
\hline $\begin{array}{l}\text { C-peptide/B-chain } \\
\text { junction }\end{array}$ & $\mathrm{R} 55 \mathrm{C}$ & c. $163 \mathrm{C}>\mathrm{T}$ & Heterozygous & $2 / 5$ & T1BDM (2) / MODY (3) & {$[15,26]$} \\
\hline C-peptide & Q62X & c. $184 \mathrm{C}>\mathrm{T}$ & Homozygous & $1 / 1$ & PNDM & {$[32]$} \\
\hline C-peptide & L68M & c. $202 \mathrm{C}>\mathrm{A}$ & Heterozygous & $1 / 1$ & T2DM* & {$[14]$} \\
\hline C-peptide & G84R & c. $250 \mathrm{G}>\mathrm{A}$ & Heterozygous & $1 / 1$ & PNDM* & {$[14]$} \\
\hline $\begin{array}{l}\text { C-peptide/ A-chain } \\
\text { junction }\end{array}$ & $\mathrm{R} 89 \mathrm{C}$ & c. $265 \mathrm{C}>\mathrm{T}$ & Heterozygous & $13 / 20$ & PNDM (15) / T1BDM (5) & {$[13,14,16,17,24]$} \\
\hline A-chain & G90C & c. $268 \mathrm{G}>\mathrm{T}$ & Heterozygous & $2 / 2$ & PNDM & {$[13,14]$} \\
\hline A-chain & $\mathrm{C} 95 \mathrm{Y}$ & c. $284 \mathrm{G}>\mathrm{A}$ & Heterozygous & $1 / 1$ & PNDM & {$[17]$} \\
\hline A-chain & $\mathrm{C} 96 \mathrm{Y}$ & c. $287 \mathrm{G}>\mathrm{A}$ & Heterozygous & $5 / 7$ & PNDM (6) / T1BDM (1) & {$[14,16,25]$} \\
\hline A-chain & $\mathrm{C} 96 \mathrm{~S}$ & c. $287 \mathrm{G}>\mathrm{C}$ & Heterozygous & $1 / 1$ & PNDM & {$[14]$} \\
\hline A-chain & S101C & c. $302 \mathrm{C}>\mathrm{G}$ & Heterozygous & $2 / 3$ & PNDM & {$[14]$} \\
\hline A-chain & Y103C & c. $308 \mathrm{~A}>\mathrm{G}$ & Heterozygous & $1 / 1$ & PNDM & [14] \\
\hline A-chain & Y108C & c. $323 \mathrm{~A}>\mathrm{G}$ & Heterozygous & $1 / 2$ & PNDM & [14] \\
\hline A-chain & Y108X & c. $324 \mathrm{C}>\mathrm{G}$ & Heterozygous & $1 / 1$ & PNDM & [17] \\
\hline 3' UTR & - & c. $59 \mathrm{~A}>\mathrm{G}$ & Homozygous & $1 / 1$ & PNDM & {$[32]$} \\
\hline
\end{tabular}

Mutations associated with hyperinsulinemia and hyperproinsulinemia are not included in this table

*Uncertain pathogenicity. TIBDM, type 1b diabetes mellitus; T2DM, type 2 diabetes mellitus; GDM, gestational diabetes mellitus; IGT, impaired glucose tolerance; 3' UTR, 3'-untranslated region 


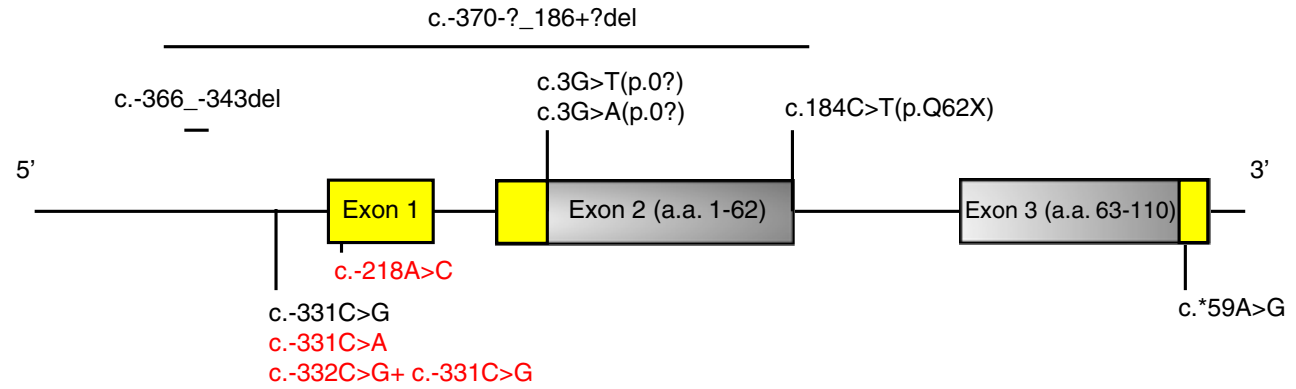

Fig. 3 A schematic of the human insulin gene showing the locations of mutations in the homozygous or compound heterozygous state in probands with PNDM and TNDM. Mutations involving coding regions are shown above the gene while those involving non-coding regions are shown below the gene. The protein coding regions of the gene are shown in gray and the regions encoding the $5^{\prime}$ - and $3^{\prime}$-untranslated regions of insulin mRNA in yellow. The red and black text indicates mutations identified in probands with TNDM and PNDM, respectively. Exon 2 encodes amino acids (a.a.) 1-62 and exon 3 encodes amino acids 63-110 of the preproinsulin molecule. Adapted from Garin et al. [32]
mRNA processing: three single base substitutions and a 24-base pair deletion are located in the promoter and one single base substitution is in the 3 '-untranslated region (3'-UTR). One patient was a compound heterozygote for two promoter mutations. Four homozygous mutations have been identified that affect the coding regions of INS: two different mutations that result in mutation of the translational initiation site (M1I), a large deletion of exons 1 and 2 (M1_Q62del) and a nonsense mutation in the $\mathrm{C}$-peptide region (Q62X). The site in the promoter at c.-331 seems to be a mutational hotspot, with seven probands identified with mutations at this site (c.-331C $>\mathrm{G}$ and c. $-331 \mathrm{C}>\mathrm{A})$.

\subsection{Clinical characteristics of patients with PNDM} due to heterozygous (dominant-negative) insulin mutations

The majority of patients with heterozygous mutations in INS were diagnosed with diabetes before 6 months of age
( $85 \%$ in the Exeter cohort). However, in contrast to the majority of patients with mutations in KCNJ11 or $A B C C 8$, INS mutations have also been found in patients diagnosed from 6-12 months of age. Ninety-six percent of patients with a heterozygous INS mutation in the Exeter cohort were diagnosed with diabetes in the first year of life. The age-atdiagnosis of diabetes (excluding patients with the mutations R6C/H, L30M, R46Q and R55C) varies from 0-1,560 weeks with a median of 11 weeks in the Exeter cohort and 26 weeks in the remaining patients. In contrast to the Akita mouse where there appears to be a difference in age-at-onset of diabetes between male and female mice (with males having an earlier onset with more severe hyperglycemia, at least on a C57BL/6 background) [18], there is no difference in age-at-diagnosis between male and female human carriers of a heterozygous INS gene mutation. Both male and female human carriers present with severe beta-cell failure at diagnosis including, in some instances, diabetic ketoacidosis or severe symptomatic

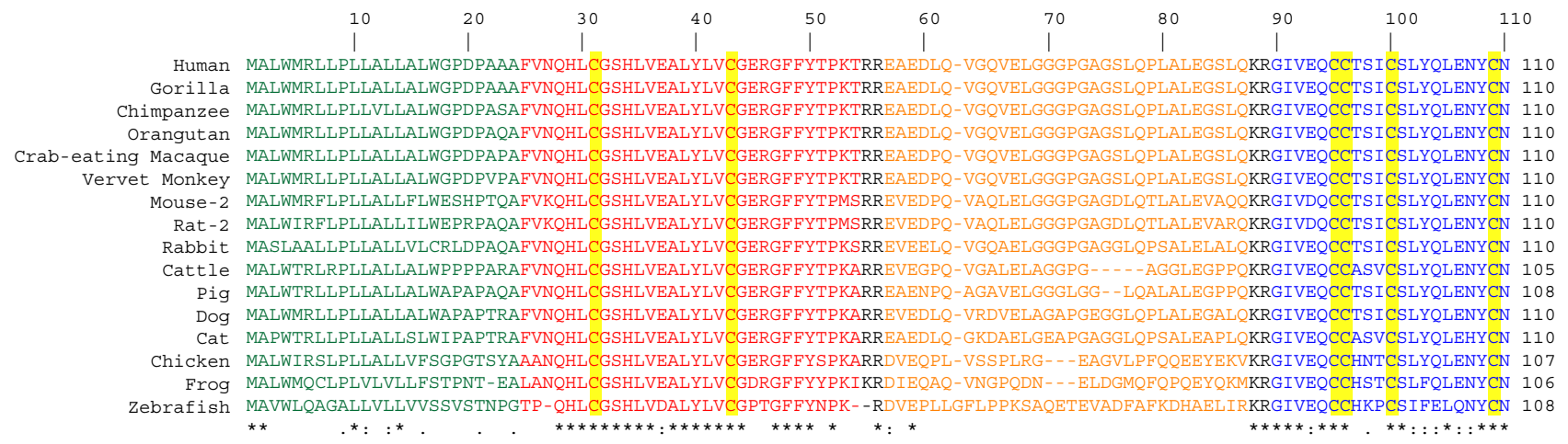

Fig. 4 Multiple sequence alignment of preproinsulin from fish to human. The ClustalW2 alignment was obtained using the online interface at EBI (http://www.ebi.ac.uk/Tools/clustalw2/index.html). The sequence of the signal peptide is shown in green letters, the Bchain in red, the C-peptide in orange and A-chain in blue. The basic amino acids that flank the C-peptide and are the sites of proteolytic processing are shown in black letters. The conserved Cys residues are highlighted in yellow. Asterisks (*) indicate identical amino acids in all the sequences shown in this alignment, colons (:) indicate conserved residues and periods (.) indicate semi-conserved amino acids. Note that these do not represent all the known preproinsulin sequences but rather are a selection of representative sequences 
hyperglycemia, a sign of almost complete insulin deficiency. The majority of patients are treated with insulin in full replacement doses [14].

Mutation carriers are born small for gestational age with median birth weights from 2,700-3,087 g (6th to 27th percentile) most likely reflecting in utero insulin deficiency. Interestingly, male carriers have been reported to have more severe growth retardation than female carriers [14].

More than half of patients with diabetes due to a heterozygous INS mutation have been screened for the presence of beta-cell auto-antibodies (anti-GAD65, islet cell antibodies (ICA) and insulin antibodies). There were no detectable auto-antibodies except for anti-insulin antibodies in some patients, most likely secondary to longstanding insulin therapy. The majority of patients had no residual beta-cell function as evidenced by low or undetectable basal or stimulated C-peptide levels. These measurements were in most cases performed months or years after the diagnosis of diabetes. However in one study, the C-peptide levels were determined at onset of diabetes and in most patients at one or two other times. These data suggest a gradual and progressive decline in beta-cell function over time. Six of 11 patients had normal, and in some instances, high C-peptide level at diagnosis of diabetes, declining levels at the repeat measurements and finally undetectable C-peptide months or years after the onset of diabetes [17].

Neurological dysfunction is a key feature of the phenotype of some patients with PNDM due to mutations in KCNJ11 or ABCC8 [33-35]. Patients with INS mutations do not have other associated extra-pancreatic features. Some patients have complications secondary to longstanding diabetes such as neuropathy and retinopathy. Signs of insulin resistance (e.g. the presence of acanthosis nigricans) have been noted in some overweight patients [13].

\subsection{Clinical characteristics of patients with MODY}

A subgroup of INS mutations is found exclusively in patients diagnosed with diabetes outside infancy and early childhood: R6H, R6C, L30M, R46Q and R55C. These patients fulfill traditional MODY criteria: non-obese, diagnosis generally $<25$ years of age and a family history of diabetes consistent with autosomal dominant inheritance. The diabetes is non-ketotic and the patients are treated with diet, oral hypoglycemic agents (OHA) or insulin. The majority of patients have residual beta-cell function as evidenced by detectable C-peptide levels. The extent of beta-cell failure could also be progressive, as some patients have declining C-peptide levels over time. One exception to the generally mild phenotype of this group of patients is a Norwegian family with the R55C mutation. The proband and her mother were diagnosed with diabetes under the dramatic setting of diabetic ketoacidosis and they now both require insulin in full replacement doses. A French family with the same mutation has mild, non-ketotic diabetes. This variation is presumably due to differences in genetic background and its effect on diabetes phenotype. Carriers of the R6H, R6C, L30M, R46Q and R55C mutations appear to have a normal birth weight (median, 4,000 g). However, birth weight in this group may be influenced by the presence of diabetes in the mothers and more studies are required to clarify the effect of these mutations on birth weight $[14,15,26,27]$.

The relationship between genotype (i.e. specific INS mutation) and phenotype is beginning to emerge from the studies to date. Some mutations (R6C/H, L30M, R46Q and $\mathrm{R} 55 \mathrm{C})$ are associated with a later age-at-diagnosis and a milder clinical course with patients maintaining adequate glycemic control on diet or oral hypoglycemic agents alone. However, the majority of INS mutations results in diabetes in the neonatal period and requires treatment with replacement doses of insulin. There can be, however, differences in the age-at-diagnosis of diabetes between carriers with the same mutation even within the same family indicating the role of other factors (genetic and nongenetic) in modifying the effect of the mutant protein on beta-cell function.

\subsection{Clinical characteristics of patients with neonatal} diabetes due to homozygous or compound heterozygous mutations

The phenotype of patients with diabetes due to a homozygous (or compound heterozygous) mutation in INS is characterized by severe intrauterine growth retardation (birth weight, $<1$ percentile) and diabetes most likely reflecting severe insulin deficiency in the pre- and postnatal life, respectively. The majority of patients are diagnosed with diabetes in the first days or weeks of life. Again, there are no extrapancreatic manifestations.

The diabetes in this group of patients can be permanent or transient. The patients with PNDM appear to have lower birth weights (median SD scores for birth weight -3.9 vs. $-1.8, P=0.03)$ and diabetes diagnosed earlier in life (2 days vs. 24 days, $P=0.04$ ) when compared to patients with TNDM. The mutations c. $-366-343 \mathrm{del}$, c. $3 \mathrm{G}>\mathrm{A}$ (p.0?), c. $3 \mathrm{G}>\mathrm{T}$ (p.0?), c. $184 \mathrm{C}>\mathrm{T}$ (p.Q62X), c. $-370-? 186+? \mathrm{del})$ and $c . * 59 A>G)$ appear to be associated with PNDM whereas the mutations at c. -218 and c. -331 have been identified in patients with both PNDM $(n=6)$ and TNDM $(n=5)$ as well as type $1 \mathrm{~b}$ diabetes $(n=2)$.

Interestingly, the carrier parents (i.e. heterozygous for the mutation) of patients who are homozygous or compound heterozygous for an INS mutation have normal glucose tolerance indicating that a single insulin allele is sufficient to provide the insulin required to maintain normal glycemia. 


\section{Insulin gene mutations and diabetes in animal models}

Two mouse models of diabetes due to dominantly-acting heterozygous insulin gene mutations have been described, the Akita (Ins $\left.2^{C 96 Y}\right)$ and the Munich (Ins2 $\left.{ }^{C 95 S}\right)$ mouse [18, 19]. The C96Y mutation has also been reported in humans. The mutation C95S has not yet been described suggesting additional human mutations will be found. Hyperglycemia and hypoinsulinemia develop from the fourth week of life. Male mice have a more severe phenotype with pronounced polydipsia, polyuria, growth retardation and high mortality rates. By contrast, female mice have only mild hyperglycemia and normal life expectancy. This sexual dimorphism remains unexplained, but could be related to protective effects of estrogen.

Akita mice have reduced numbers of beta cells and reduced pancreatic insulin content. There is no evidence of inflammation of the islets as seen in islets from patients with type 1 diabetes. Electron microscopic studies of beta cells from diabetic Akita mice reveal severe organelle dysfunction with enlarged ER, swollen mitochondria, prominent lysosomes and a reduced number of secretory granules. These findings are consistent with a block in the progression of mutant proinsulin (and possibly some normal proinsulin) from the ER to the Golgi apparatus accompanied by ER stress. The accumulation of misfolded mutant proinsulin in the ER leads to activation of the unfolded protein response (UPR) including expression of the pro-apoptotic $C H O P$ gene. In this regard, the development of diabetes is delayed by $8-10$ weeks in Akita mice lacking $C H O P$ highlighting the role of the UPR and apoptosis in beta-cell death in this model. Further studies of the Akita and Munich mouse models could lead to a better understanding of the pathophysiology of diabetes due to expression of a mutant proinsulin protein and perhaps novel approaches for treating this form of diabetes $[31,36]$.

\section{Pathophysiology of insulin mutations}

\subsection{Structure/function studies of insulin mutations}

Studies of the effects of mutations that affect processing of preproinsulin to proinsulin or lead to misfolding of proinsulin have shown that the mutant proteins accumulate in the ER and are poorly secreted (Fig. 5). The expression

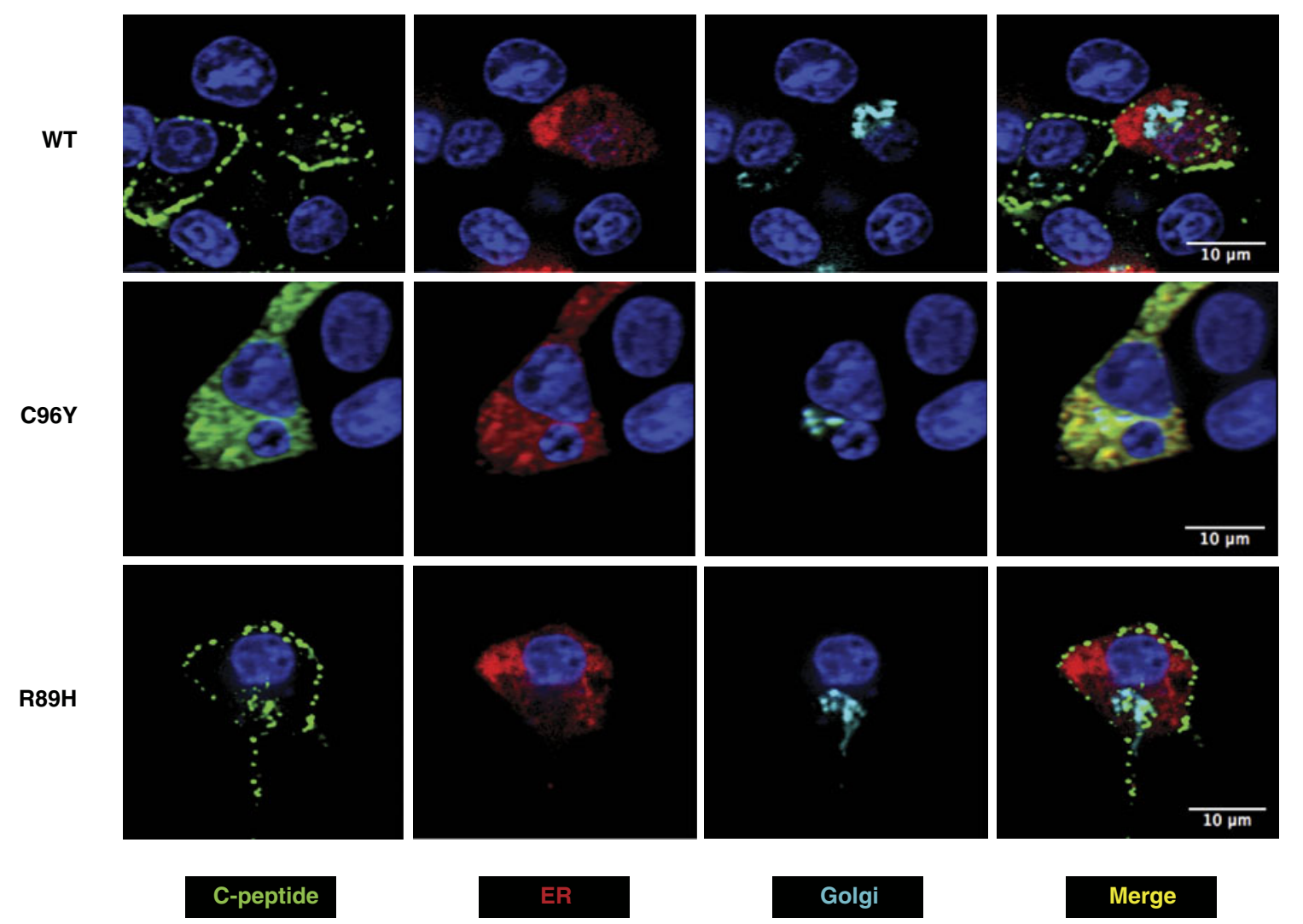

Fig. 5 Subcellular localization of wild-type (WT) and mutant human proinsulin expressed in rat INS-1 insulinoma cells [30]. The location of human C-peptide immunoreactive protein is shown in green, ER is shown in red and the Golgi marker in cyan. Nuclei were stained with DAPI (blue). The WT and R89H hyperproinsulinemia mutant proinsulins are localized to secretory granules. By contrast, the C96Y PNDM-associated mutant proinsulin is localized to the expanded ER and is not transported from the ER to the Golgi and packaged into secretory granules 
of the mutant proteins also leads to induction of the UPR and in time apoptosis. The mutant proteins also appear to exert a dominant-negative effect on the synthesis and secretion of native proinsulin due to induction of the UPR and consequent attenuation of translation [17, 29, 30].

Hodish et al. (2010) have established an elegant transgenic model to study the effect of the C96Y mutation on insulin biosynthesis in vivo by crossing transgenic mice expressing GFP-tagged proinsulin with Akita mice. They show that the mutant (C96Y) proinsulin blocks native proinsulin biosynthesis followed by loss of pancreatic betacells. Thus, the aggregation of both mutant and native proinsulin in the ER likely triggers ER stress [37].

\subsection{Pathophysiology of homozygous insulin gene mutations}

In contrast to the dominantly-acting mutations, the mutations found in the homozygous state result in diabetes through reduced insulin biosynthesis per se. These mutations affect insulin biosynthesis by distinct mechanisms including gene deletion, mutation of the translation initiation site, synthesis of a nonsense protein, impaired transcription due to mutations of critical transcription factor binding sites in the promoter, and impaired mRNA polyadenylation leading to insulin mRNA instability, all resulting in severely impaired insulin production, but without ER stress. These patients presumably have otherwise normal beta cells and the transient nature of the diabetes in some of these patients is consistent with this view [32].

\section{Insulin gene mutations and familial syndromes of hyperproinsulinemia and hyperinsulinemia with mild diabetes}

A subgroup of mutations in INS causes mild diabetes or impaired glucose tolerance by another mechanism. These mutations lead to the synthesis of an insulin with reduced biological activity or prevent processing of proinsulin to insulin leading to hyperinsulinemia or hyperproinsulinemia, respectively. In contrast to the INS mutations associated with PNDM, the beta cells are able to synthesize and secrete these molecules, thus indicating that these variants of INS do not per se lead to cellular or organelle dysfunction.

\subsection{Hyperinsulinemia}

Three rare missense mutations, F48S (insulin Los Angeles), F49L (insulin Chicago), and V93L (insulin Wakayama) (Figs. 1 and 2) have been identified in patients with phenotypes ranging from normal glycemia to mild diabetes and concomitant hyperinsulinemia [9, 38-43]. These mutations affect amino acids involved in insulin receptor binding (B24-Phe, B25-Phe and A3-Val) and as a consequence the mutant insulins have reduced insulin receptor affinity and biological activity. Mutation carriers have hyperinsulinemia, but impaired glucose tolerance or overt diabetes only develops in adults with insulin resistance. When diabetes develops, it is mild and satisfactory glycemic control can be achieved with diet, oral hypoglycemic agents or small doses of insulin.

\subsection{Hyperproinsulinemia}

Four rare heterozygous missense mutations in INS have been identified in patients with a disorder characterized by hyperproinsulinemia and a variable degree of glucose intolerance: three mutant forms of proinsulin that involve the C-peptideA chain junction (R89H (proinsulin Tokyo), R89L (proinsulin Kyoto) and R89P) and a mutation in the B-chain, H34D (proinsulin Providence) [9-12, 44-49]. The glucose intolerance varies from normal glucose tolerance to mild diabetes that can in most cases be managed with diet only.

The substitution of Arg-89 for His, Leu or Pro at the C-peptide-A-chain junction (the site of proteolytic cleavage of des-31, 32 proinsulin to insulin and C-peptide) interferes with the action of the prohormone convertase $\mathrm{PC} 2$ and as a consequence, these patients have high levels in the circulating of a proinsulin-like material that has been cleaved only at the B-chain-C-peptide junction. The INS mutation H34D causes hyperproinsulinemia by another mechanism. A proportion of newly synthesized Asp-B10 proinsulin is secreted unprocessed in a glucose-independent manner via an unregulated pathway and enters the circulation as Asp-B10 proinsulin whereas the majority enters the regulated secretory pathway and is processed and secreted as Asp-B10 insulin. The reason for the missorting of Asp-B10 proinsulin is unclear but might be related to the higher biological potency of both Asp-B10 proinsulin and insulin relative to native proinsulin and insulin which increases its binding to recycling insulin receptors in the beta cell leading to its uncontrolled release and/or lysosomal degradation [50]. Perhaps, Asp-B10 proinsulin, thus, reduces the requirement for release of normally processed insulin (including Asp-B10 insulin) by the regulated pathway.

\section{Conclusion}

Mutations in the insulin gene are associated with diverse phenotypes from hyperinsulinemia and hyperproinsulinemia to neonatal diabetes. These mutations (in both the heterozygous and homozygous state) are a common cause of neonatal diabetes. They can also be found in patients with a diagnosis of type $1 \mathrm{~b}$ diabetes or MODY. A correct genetic diagnosis in these patients is important for correct classification of their 
disease as well as for purposes of genetic counseling. Currently, there is no specific treatment for these patients apart from insulin-based regimens when this is required but future research may identify approaches for addressing the cellular stress resulting from the biosynthesis of a mutant protein and thereby preserving beta-cell function and allowing the normal allele to provide the insulin necessary for maintaining normal glucose tolerance.

Acknowledgements The research from our laboratories described in this review was supported in part by U.S. Public Health Service Grants DK-13914, DK-48494 and DK-20595 (The University of Chicago Diabetes Research and Training Center; and Diabetes Centers R24 Seeding Collaborative Interdisciplinary Team Science in Diabetes, Endocrinology and Metabolic Diseases) and a gift from the Kovler Family Foundation.

Open Access This article is distributed under the terms of the Creative Commons Attribution Noncommercial License which permits any noncommercial use, distribution, and reproduction in any medium, provided the original author(s) and source are credited.

\section{References}

1. McCarthy MI, Hattersley AT. Learning from molecular genetics: novel insights arising from the definition of genes for monogenic and type 2 diabetes. Diabetes. 2008;57(11):2889-98.

2. Sanger F. Chemistry of insulin; determination of the structure of insulin opens the way to greater understanding of life processes. Science. 1959;129(3359):1340-4.

3. Nicol DS, Smith LF. Amino-acid sequence of human insulin. Nature. 1960;187:483-5.

4. Oyer PE, Cho S, Peterson JD, Steiner DF. Studies on human proinsulin. Isolation and amino acid sequence of the human pancreatic C-peptide. J Biol Chem. 1971;246(5):1375-86.

5. Steiner DF, Cunningham D, Spigelman L, Aten B. Insulin biosynthesis: evidence for a precursor. Science. 1967;157 (789):697-700.

6. Bell GI, Swain WF, Pictet R, Cordell B, Goodman HM, Rutter WJ. Nucleotide sequence of a cDNA clone encoding human preproinsulin. Nature. 1979;282(5738):525-7.

7. Bell GI, Pictet RL, Rutter WJ, Cordell B, Tischer E, Goodman HM. Sequence of the human insulin gene. Nature. 1980;284 (5751):26-32.

8. Kimmel JR, Pollock HG. Studies of human insulin from nondiabetic and diabetic pancreas. Diabetes. 1967;16(10):68794.

9. Steiner DF, Tager HS, Nanjo K, Chan SJ, Rubenstein AH. Familial syndromes of hyperproinsulinemia and hyperinsulinemia with mild diabetes. In: Schriver C, Beaudet A, Sly W, Valle D, editors. The metabolic basis of inherited disease. New York: McGraw-Hill; 1995. p. 897-904.

10. Warren-Perry MG, Manley SE, Ostrega D, Polonsky K, Mussett $\mathrm{S}$, Brown $\mathrm{P}$, et al. A novel point mutation in the insulin gene giving rise to hyperproinsulinemia. $\mathrm{J}$ Clin Endocrinol Metab. 1997;82(5):1629-31.

11. Collinet M, Berthelon M, Bénit P, Laborde K, Desbuquois B, Munnich A, et al. Familial hyperproinsulinemia due to a mutation substituting histidine for arginine at position 65 in proinsulin: identification of the mutation by restriction enzyme mapping. Eur J Pediatr. 1998;157(6):456-60.
12. Röder ME, Vissing H, Nauck MA. Hyperproinsulinemia in a three-generation Caucasian family due to mutant proinsulin (Arg65-His) not associated with impaired glucose tolerance: the contribution of mutant proinsulin to insulin bioactivity. J Clin Endocrinol Metab. 1996;81(4):1634-40.

13. Støy J, Edghill EL, Flanagan SE, Ye H, Paz VP, Pluzhnikov A, et al. Insulin gene mutations as a cause of permanent neonatal diabetes. Proc Natl Acad Sci U S A. 2007;104(38):15040-4.

14. Edghill EL, Flanagan SE, Patch AM, Boustred C, Parrish A, Shields B, et al. Insulin mutation screening in 1, 044 patients with diabetes: mutations in the INS gene are a common cause of neonatal diabetes but a rare cause of diabetes diagnosed in childhood or adulthood. Diabetes. 2008;57(4):1034-42.

15. Molven A, Ringdal M, Nordbø AM, Raeder H, Støy J, Lipkind GM, et al. Mutations in the insulin gene can cause MODY and autoantibody-negative type 1 diabetes. Diabetes. 2008;57(4):1131-5.

16. Polak M, Dechaume A, Cavé H, Nimri R, Crosnier H, Sulmont V, et al. Heterozygous missense mutations in the insulin gene are linked to permanent neonatal diabetes appearing in the neonatal period or in early infancy: a report from the French ND (Neonatal Diabetes) study group. Diabetes. 2008;57(4):1115-9.

17. Colombo C, Porzio O, Liu M, Massa O, Vasta M, Salardi S, et al. Seven mutations in the human insulin gene linked to permanent neonatal/infancy-onset diabetes mellitus. J Clin Invest. 2008;118 (6):2148-56.

18. Wang J, Takeuchi T, Tanaka S, Kubo SK, Kayo T, Lu D, et al. A mutation in the insulin 2 gene induces diabetes with severe pancreatic beta-cell dysfunction in the Mody mouse. J Clin Invest. 1999;103 (1):27-37.

19. Herbach N, Rathkolb B, Kemter E, Pichl L, Klaften M, de Angelis $\mathrm{MH}$, et al. Dominant-negative effects of a novel mutated Ins2 allele causes early-onset diabetes and severe beta-cell loss in Munich Ins2C95S mutant mice. Diabetes. 2007;56(5):1268-76.

20. Schuit FC, Kiekens R, Pipeleers DG. Measuring the balance between insulin synthesis and insulin release. Biochem Biophys Res Commun. 1991;178(3):1182-7.

21. Van Lommel L, Janssens K, Quintens R, Tsukamoto K, Vander Mierde D, Lemaire $\mathrm{K}$, et al. Probe-independent and direct quantification of insulin mRNA and growth hormone mRNA in enriched cell preparations. Diabetes. 2006;55(12):3214-20.

22. Steiner DF, Park SY, Støy J, Philipson LH, Bell GI. A brief perspective on insulin production. Diabetes Obes Metab. 2009;11 Suppl 4:189-96.

23. Bonfanti R, Colombo C, Nocerino V, Massa O, Lampasona V, Iafusco D, et al. Insulin gene mutations as cause of diabetes in children negative for five type 1 diabetes autoantibodies. Diabetes Care. 2009;32(1):123-5.

24. Rubio-Cabezas O, Edghill EL, Argente J, Hattersley AT. Testing for monogenic diabetes among children and adolescents with antibodynegative clinically defined type 1 diabetes. Diabet Med. 2009;26 (10):1070-4.

25. Ahamed A, Unnikrishnan AG, Pendsey SS, Nampoothiri S, Bhavani N, Praveen VP, et al. Permanent neonatal diabetes mellitus due to a $\mathrm{C} 96 \mathrm{Y}$ heterozygous mutation in the insulin gene. A case report. JOP. 2008;9(6):715-8.

26. Meur G, Simon A, Harun N, Virally M, Dechaume A, Bonnefond A, et al. Insulin gene mutations resulting in early-onset diabetes: marked difference in clinical presentation, metabolic status, and pathogenic effect through endoplasmic reticulum retention. Diabetes. 2010;59(3):653-61.

27. Boesgaard TW, Pruhova S, Andersson EA, Cinek O, Obermannova $\mathrm{B}$, Lauenborg J, et al. Further evidence that mutations in INS can be a rare cause of Maturity-Onset Diabetes of the Young (MODY). BMC Medical Genetics. 2010;11:42.

28. Oda N, Nakai A, Fujiwara K, Imamura S, Fujita T, Hamagishi M, et al. Polymorphisms of the insulin gene among Japanese subjects. Metabolism. 2001;50(6):631-4. 
29. Rajan S, Eames SC, Park SY, Labno C, Bell GI, Prince VE, et al. In vitro processing and secretion of mutant insulin proteins that cause permanent neonatal diabetes. Am J Physiol Endocrinol Metab. 2010;298(3):E403-10.

30. Park SY, Ye H, Steiner DF, Bell GI. Mutant proinsulin proteins associated with neonatal diabetes are retained in the endoplasmic reticulum and not efficiently secreted. Biochem Biophys Res Commun. 2010;391(3):1449-54.

31. Izumi T, Yokota-Hashimoto H, Zhao S, Wang J, Halban PA, Takeuchi T. Dominant negative pathogenesis by mutant proinsulin in the Akita diabetic mouse. Diabetes. 2003;52(2):409-16.

32. Garin I, Edghill EL, Akerman I, Rubio-Cabezas O, Rica I, Locke $\mathrm{JM}$, et al. Recessive mutations in the INS gene result in neonatal diabetes through reduced insulin biosynthesis. Proc Natl Acad Sci USA. 2010;107(7):3105-10.

33. Gloyn AL, Pearson ER, Antcliff JF, Proks P, Bruining GJ, Slingerland AS, et al. Activating mutations in the gene encoding the ATP-sensitive potassium-channel subunit Kir6.2 and permanent neonatal diabetes. N Engl J Med. 2004;350 (18):1838-49.

34. Flanagan SE, Clauin S, Bellanné-Chantelot C, de Lonlay $P$, Harries LW, Gloyn AL, et al. Update of mutations in the genes encoding the pancreatic beta-cell K(ATP) channel subunits Kir6.2 (KCNJ11) and sulfonylurea receptor 1 (ABCC8) in diabetes mellitus and hyperinsulinism. Hum Mutat. 2009;30 (2): $170-80$.

35. Babenko AP, Polak M, Cavé H, Busiah K, Czernichow P, Scharfmann R, et al. Activating mutations in the ABCC8 gene in neonatal diabetes mellitus. N Engl J Med. 2006;355(5):456-66.

36. Oyadomari S, Koizumi A, Takeda K, Gotoh T, Akira S, Araki E, et al. Targeted disruption of the Chop gene delays endoplasmic reticulum stress-mediated diabetes. J Clin Invest. 2002;109 (4):525-32.

37. Hodish I, Liu M, Rajpal G, Larkin D, Holz RW, Adams A, et al. Misfolded proinsulin affects bystander proinsulin in neonatal diabetes. J Biol Chem. 2010;285(1):685-94.

38. Haneda M, Polonsky KS, Bergenstal RM, Jaspan JB, Shoelson SE, Blix PM, et al. Familial hyperinsulinemia due to a structurally abnormal insulin. Definition of an emerging new clinical syndrome. N Engl J Med. 1984;310(20):1288-94.

39. Nanjo K, Sanke T, Miyano M, Okai K, Sowa R, Kondo M, et al. Diabetes due to secretion of a structurally abnormal insulin (insulin Wakayama). Clinical and functional characteristics of [LeuA3] insulin. J Clin Invest. 1986;77(2):514-9.

40. Nanjo K, Miyano M, Kondo M, Sanke T, Nishimura S, Miyamura $\mathrm{K}$, et al. Insulin Wakayama: familial mutant insulin syndrome in Japan. Diabetologia. 1987;30(2):87-92.

41. Tager H, Given B, Baldwin D, Mako M, Markese J, Rubenstein A, et al. A structurally abnormal insulin causing human diabetes. Nature. 1979;281(5727):122-5.

42. Given BD, Mako TE, Tager HS, Baldwin D, Markese J, Rubenstein AH, et al. Diabetes due to secretion of an abnormal insulin. N Engl J Med. 1980;302(3):129-35.

43. Iwamoto $Y$, Sakura H, Ishii U, Yamamoto R, Kumakura $\mathrm{S}$, Sakamoto Y, et al. A new case of abnormal insulinemia with diabetes. Diabetes. 1986;35(11):1237-42.

44. Gabbay KH, Bergenstal RM, Wolff J, Mako ME, Rubenstein AH. Familial hyperproinsulinemia: partial characterization of circulating proinsulin-like material. Proc Natl Acad Sci USA. 1979;76(6):2881-5.

45. Yano H, Kitano N, Morimoto M, Polonsky KS, Imura H, Seino Y. A novel point mutation in the human insulin gene giving rise to hyperproinsulinemia (proinsulin Kyoto). J Clin Invest. 1992;89 (6):1902-7.

46. Oohashi H, Ohgawara H, Nanjo K, Tasaka Y, Cao QP, Chan SJ, et al. Familial hyperproinsulinemia associated with NIDDM. A case study. Diabetes Care. 1993;16(10):1340-6.

47. Shibasaki Y, Kawakami T, Kanazawa Y, Akanuma Y, Takaku F. Posttranslational cleavage of proinsulin is blocked by a point mutation in familial hyperproinsulinemia. J Clin Invest. 1985;76 (1):378-80.

48. Gruppuso PA, Gorden P, Kahn CR, Cornblath M, Zeller WP, Schwartz R, et al. Familial hyperproinsulinemia due to a proposed defect in conversion of proinsulin to insulin. $\mathrm{N}$ Engl J Med. 1984;311(10):629-34.

49. Barbetti F, Raben N, Kadowaki T, Cama A, Accili D, Gabbay KH, et al. Two unrelated patients with familial hyperproinsulinemia due to a mutation substituting histidine for arginine at position 65 in the proinsulin molecule: identification of the mutation by direct sequencing of genomic deoxyribonucleic acid amplified by polymerase chain reaction. J Clin Endocrinol Metab. 1990;71(1):164-9.

50. Carroll RJ, Hammer RE, Chan SJ, Swift HH, Rubenstein AH, Steiner DF. A mutant human proinsulin is secreted from islets of Langerhans in increased amounts via an unregulated pathway. Proc Natl Acad Sci USA. 1988;85(23):8943-7. 